\title{
Correction to: Mobile Technology in Pacific Island Countries: the Potential for M-Government
}

Amanda H. A. Watson, Joseph Kim Suwamaru, Ioana Chan Mow

and Sarah Logan

Correction to:

Chapter 5 in: R. Cullen and G. Hassall (eds.), Achieving Sustainable E-Government in Pacific Island States, Public Administration and Information Technology 27, https://doi.org/10.1007/978-3-319-50972-3_5

The following corrections were incorporated in the chapter "Mobile Technology in Pacific Island Countries: the Potential for M-Government":

The authors' affiliation “Amanda Watson, Department of Government and International Relations, University of Sydney, Sydney, Australia and Sarah Logan, Australian National University, Canberra, Australia" has been corrected to "Amanda H. A. Watson, Australian National University, Canberra, Australia and Sarah Logan, University of New South Wales, Sydney, Australia" in this chapter.

The erratum book had been updated with these changes.

The updated original online version for this chapter can be found at https://doi.org/10.1007/978-3-319-50972-3_5 